\title{
КРАТКИЕ СООБЩЕНИЯ
}

(с) Коллектив авторов, 2020

уДК 612.115.064

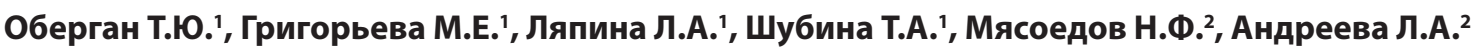

\section{Влияние пептидов глипролинового ряда}

на уровень метаболитов оксида азота

\section{и активность тканевого активатора плазминогена у крыс в норме и при метаболическом синдроме}

\author{
'ФГБОУ ВО «Московский государственный университет им. М.В. Ломоносова», \\ 119234, Москва, Россия, Ленинские горы, д. 1/12; \\ 2 ФГБУН «Институт молекулярной генетики» Российской академии наук, \\ 123182, Москва, Россия, ул. Курчатова, д. 2
}

Введение. Короткие регуляторные пролинсодержащие пептиды могут оказывать противосвертывающие эффекты в организме и проявлять защитное действие при тромбозах.

Цель исследования - выявление косвенных эффектов пептидов глипролинового ряда Pro-Gly-Pro (PGP) и Arg-Glu-ArgPro-Gly-Pro (RERPGP) на функцию эндотелия сосудов и состояние системы фибринолиза в норме и при нарушении липидного обмена.

Методика. Пептиды были синтезированы в институте молекулярной генетики РАН. В экспериментах использовано 60 лабораторных белых крыс-самцов линии Wistar. Проведено 2 серии экспериментов - на здоровых крысах и животных с экспериментально воспроизведенным метаболическим синдромом (МС). Пептиды вводили интраназально в течение 7 сут через каждые 24 ч (100 мкг/кг) ежедневно. Анализ крови осуществляли через 20 и 168 ч после завершающего введения пептидов. Определяли уровни метаболитов оксида азота (NO) и активности тканевого активатора плазминогена (ТАП).

Результаты. Выявлены различия в действии PGP и RERPGP на исследуемые параметры у здоровых животных. В плазме крови крыс через 20 ч после семикратного введения пептида PGP установлено значительное повышение активности TAП и метаболитов NO, которое сохранялось на протяжении 168 ч эксперимента, в то время как под влиянием RERPGP отмечалось повышение только уровня нитратов и нитритов через 168 ч после его применения. Пептид PGP также оказывал выраженные эффекты на функцию эндотелия организма и при развитии МС. Активность ТАП значительно и статистически значимо увеличивалась через 20 ч после семикратного введения пептида, эти изменения наблюдались также спустя 168 ч после применения PGP. Эти величины практически соответствовали значениям ТАП у здоровых крыс. Уровень метаболитов NO также значимо повышался при воздействии PGP на фоне МС. Сделано предположение о возможных механизмах действия пептидов на сосудистый эндотелий.

Заключение. Пептиды глипролинового ряда оказывали стимулирующее влияние на функцию эндотелия в организме как в норме, так и при патологии, повышая активность тканевого активатора плазминогена и концентрацию метаболитов оксида азота.

Ключевые слова: пептиды PGP, RERPGP; метаболический синдром; нитраты/нитриты; тканевой активатор плазминогена; функция эндотелия

Для цитирования: Оберган Т.Ю., Григорьева М.Е., Ляпина Л.А., Шубина Т.А., Мясоедов Н.Ф., Андреева Л.А. Влияние пептидов глипролинового ряда на уровень метаболитов оксида азота и активность тканевого активатора плазминогена у крыс в норме и при метаболическом синдроме. Патологическая физиология и экспериментальная терапия. 2020; 64(4): 88-94.

DOI: $10.25557 / 0031-2991.2020 .04 .88-94$

Для корреспонденции: Оберган Тамара Юрьевна, e-mail: tobergan@mail.ru

Участие авторов: концепция и дизайн исследования - Мясоедов Н.Ф., Ляпина Л.А.; проведение эксперимента, сбор и обработка материала - Ляпина Л.А., Оберган Т.Ю., Григорьева М.Е., Шубина Т.А., Андреева Л.А., подготовка иллюстративного материала - Оберган Т.Ю., статистическая обработка - Андреева Л.А., Оберган Т.Ю., написание текста - Оберган Т.Ю., Шубина Т.А., редактирование - Ляпина Л.А., Григорьева М.Е.; утверждение окончательного варианта статьи - все авторы. 
Финансирование. Исследование выполнено при финансовой поддержке гранта РФФИ, конкурс проектов 2018 года фундаментальных научных исследований Грант № 18-04-00260.

Конфликт интересов. Авторы заявляют об отсутствии конфликта интересов.

Поступила 25.11.2019

Принята в печать 16.10.2020

Опубликована 26.11.2020

Obergan T.Yu. ${ }^{1}$, Grigorjeva M.E. ${ }^{1}$, Lyapina L.A. ${ }^{1}$, Shubina T.A. ${ }^{\text {, }}$ Myasoedov N.F. ${ }^{2}$, Andreeva L.A. ${ }^{2}$

The effect of glyproline peptides on levels of nitric oxide metabolites and tissue plasminogen activator activity in healthy rats and rats with metabolic syndrome

\author{
'M.V. Lomonosov Moscow State University, \\ Leninskie Gory 1/12, Moscow, 119234, Russia; \\ ${ }^{2}$ Institute of Molecular Genetics of the Russian Academy of Sciences, \\ Kurchatova Str. 2, Moscow, 123182, Russia
}

Short regulatory proline-containing peptides can exert an anticoagulation effect and be protective in thrombosis.

The aim of this study was to identify indirect effects of glyproline peptides Pro-Gly-Pro (PGP) и Arg-Glu-Arg-Pro-Gly-Pro (RERPGP) on vascular endothelial function and the fibrinolytic system in normal and impaired lipid metabolism.

Methods. Peptides were synthesized at the Institute of Molecular Genetics, Russian Academy of Sciences. Experiments were performed on 60 male Wistar rats divided into healthy animals and animals with experimental metabolic syndrome (MS). Peptides $(100 \mu \mathrm{g} / \mathrm{kg})$ were administered intranasally, once a day for 7 days. Blood tests were performed $20 \mathrm{~h}$ and $168 \mathrm{~h}$ after the last administration of the peptides. Concentrations of nitric oxide (NO) metabolites (sum plasma concentration of nitrate and nitrite) and the activity of tissue plasminogen activator (TAP) were measured.

Results. The effects of PGP and RERPGP on the endothelial function in healthy animals were different. Significant increases in both TAP activity and NO metabolite concentration were found in plasma $20 \mathrm{~h}$ after 7 PGP administrations, which persisted throughout $168 \mathrm{~h}$ of the experiment. Only an increase in nitrate/nitrite was observed at $168 \mathrm{~h}$ after the RERPGP administration. PGP also exerted pronounced effects on the endothelial function, including in MS. TAP activity was significantly increased at $20 \mathrm{~h}$ after 7 administrations of the peptide, and this effect remained at $168 \mathrm{~h}$ after the PGP administration. These values were practically similar to the TAP values in healthy rats. Concentrations of NO metabolites were also significantly increased after the PGP exposure of MS rats. Possible mechanisms for the peptide activation of vascular endothelium are discussed.

Conclusion. Glyproline peptides had a stimulatory effect on the endothelial function both in normal and pathological conditions by increasing the TAP activity and the concentration of NO metabolites.

Keywords: glyproline; PGP, RERPGP; metabolic syndrome; nitrate/nitrite; tissue plasminogen activator; endothelial function For citation: Obergan T.Yu., Grigorjeva M.E., Lyapina L.A., Shubina T.A., Myasoedov N.F., Andreeva L.A. The effect of glyproline peptides on levels of nitric oxide metabolites and tissue plasminogen activator activity in healthy rats and rats with metabolic syndrome. Patologicheskaya Fiziologiya i Eksperimental naya terapiya. (Pathological Physiology and Experimental Therapy, Russian Journal). 2020; 64(4): 88-94. (in Russian).

DOI: 10.25557/0031-2991.2020.04.88-94

For correspondence: Obergan Tamara Yurievna, senior scientific Department of Human and Animal Physiology, Laboratory Protective Blood Systems named after prof. B.A. Kudryashov, e-mail: tobergan@mail.ru

Conflict of interest. The authors declare no conflict of interest.

Acknowledgment. The study was supported by an RFBR grant for basic research projects 2018 (project \# 18-04-00260).

Contribution: research concept and design - Myasoedov N.F., Lyapina L.A., performing an experiment, material collecting and processing Lyapina L.A., Obergan T.Yu., Grigorjeva M.E., Shubina T.A., Andreeva L.A., preparation of illustrative material - Obergan T.Yu, statistical processing - Andreeva L.A., Obergan T.Yu.; writing text - Obergan T.Yu., Lyapina L.A., Grigorjeva M.E., Shubina T.A.; text editing - Lyapina L.A., Myasoedov N.F. Approval of the final version of the article - all co-authors.

Information about the authors:

Obergan T.Yu., http://orcid.org/0000-0002-3760-3943

Grigorjeva M.E., http://orcid.org/0000-0003-0469-3943

Lyapina L.A., http://orcid.org/0000-0002-8983-652X

Shubina T.A., http://orcid.org/0000-0003-1092-8382

Myasoedov N.F., http://orcid.org/0000-0003-1294-102X

Andreeva L.A., http://orcid.org/0000-0002-3927-8590

Reseived 25.11.2019

Accepted 16.10.2020

Published 26.11.2020 


\section{Введение}

Эндотелий сосудов участвует в регуляции многих систем организма, в том числе гемостаза, кровообращения, сосудистого тонуса, вырабатывая различные биологически активные вещества. Одно из этих веществ оксид азота (NO) служит и вазодилататором, и антиагрегантом [1]. NO в организме человека и животных образуется из аминокислоты L-аргинин при участии NO-синтаз $[2,3]$. По механизму действия NO является основным стимулятором образования цГМФ. При этом в тромбоцитах уменьшается содержание кальция, который вовлекается во все фазы процесса свертывания крови. Одним из важнейших механизмов действия NO служит активирование кальциевых каналов [4]. Кроме того, NO относится к индукторам тканевого активатора плазминогена (ТАП) [5, 6]. При патологических состояниях, осложняющихся повышением свертываемости крови, наблюдается снижение синтеза NO, что отражает дисфункцию эндотелия [7]. О выработке NO в организме косвенно свидетельствует количество его метаболитов (нитратов и нитритов). В настоящее время считается, что для оценки эндотелиальной дисфункции также может быть использован тканевой активатор плазминогена (ТАП) [8], основной функцией которого является участие в процессах ферментативного фибринолиза. Комплексным заболеванием, которое характеризуется нарушениями углеводного и липидного обмена, а также гиперкоагуляцией, гипофибринолизом и депрессией (дисфункцией) эндотелия сосудов является метаболический синдром (MC) [9].

Известно, что пролинсодержащие пептиды обладают эндотелий-зависимой реакцией экскреции в кровоток ТАП. Кроме того, короткие регуляторные пептиды оказывают антитромбоцитарный и антикоагулянтный эффекты в организме $[10,11]$. Доказана защитная роль регуляторных пептидов при нарушениях функции гемостаза, сопровождающихся расстройствами углеводного и липидного обмена веществ [12].

Цель исследования - выявление косвенных эффектов пептидов глипролинового ряда Pro-Gly-Pro (PGP) и Arg-Glu-Arg-Pro-Gly-Pro (RERPGP) на функцию эндотелия сосудов по выработке-метаболитов NO (нитратов и нитритов) и состояние системы фибринолиза по активности тканевого активатора плазминогена.

\section{Методика}

Исследование выполнено на 60 лабораторных белых крысах-самцах линии Wistar с массой тела 230-250 г, полученных из питомника лабораторных животных
«Столбовая» ФГБУН НЦБМТ ФМБА России. Животные содержались в стандартных условиях вивария при свободном доступе к воде и пище. Все эксперименты были проведены с соблюдением этических принципов работы с животными в соответствии с «Европейской Конвенцией о защите позвоночных животных, используемых для экспериментов или в иных научных целях» (ETS № 123, Страсбург, 18.03.1986 г. с приложением от 15.06.2006) и «Правилами надлежащей лабораторной практики» (приказ МЗ РФ № 199н от 01.04.2016).

Исследуемые в работе пептиды PGP и RERPGP были синтезированы в институте молекулярной генетики РАН. Для инъекции препаратов животным навеску каждого из пептидов ежедневно растворяли в физиологическом растворе, затем вводили животным (доза 100 мкг/кг в объеме 20 мкл) интраназально в течение 7 сут через каждые 24 ч.

Проведено 2 серии экспериментов - на здоровых крысах и животных с экспериментально воспроизведенным метаболическим синдромом (МС). 30 здоровых крыс (1-я серия экспериментов) были разделены на 3 группы по10 животных в каждой: контроль (группа 1), введение пептидов PGP (группа 2) или RERPGP (группа 3). Контрольные животные получали по 20 мкл физиологического раствора.

Для проведения 2-й серии экспериментов использовали модель метаболического синдрома [11]. Метаболические нарушения у животных индуцировали высококалорийной диетой (ВКД), включающей избыток насыщенных жирных кислот, холестерина и углеводов. Калорийность ВКД составляла не менее 3894 ккал/кг, т.е. $132 \%$ от калорийности стандартного гранулированного корма (2950 ккал/кг). Ранее нами было установлено, что содержание крыс на ВКД приводит к развитию у животных МС, т.е. увеличению избыточной массы тела, нарушениям липидного и углеводного обмена, а также к нарушениям нормального функционирования системы гемостаза. Через 6 нед ВКД, животные были разделены на 2 группы: в 1-й группе крысам с МС вводили физиологический раствор («МС + $\mathrm{NaCl}, n=10)$, крысам 2-й - пептид PGP («MC + PGP», $n=10)$ в дозе 100 мкг/кг, интраназально, 7-кратно через каждые 24 ч. Дополнительно использовали группу здоровых интактных животных («Здоровые», $n=10$ ).

Через 20 и 168 ч после 7-го введения пептидов брали образцы крови от каждого животного. В богатой тромбоцитами плазме крови оценивали функцию эндотелия по уровню метаболитов NO (нитратов и нитритов) и состояние системы фибринолиза по активности тканевого активатора плазминогена (ТАП). Суммарную концентрацию нитратов и нитритов измеряли 
методом Грисса в реакции азосочетания N-(нафтил) этилендиамина с сульфаниламидом в присутствии азотистой кислоты. Далее для реакции восстановления нитратов в нитриты использовали хлорид ванадия [3]. Величину оптической плотности измеряли на сканере Multiskan FX (Labsystem, США). Активность ТАП оценивали на стандартных пластинах фибрина по разнице зон лизиса на прогретых при $86{ }^{\circ} \mathrm{C}$ и непрогретых пленках [13].

Статистический анализ данных осуществляли, используя пакет статистических программ Statistica 8 (StatSoft Inc., США), а также графических программ Microsoft Excel. Оценку нормальности эмпирических распределений проводили с использованием критерия Шапиро-Уилка. Дальнейшую обработку данных проводили с применением непараметрических методов Краскела-Уоллиса и Манна-Уитни. Полученные результаты представлены как среднее значение \pm стандартная ошибка среднего ( \pm 土 SEM). Различия считали статистически значимыми при $p<0,05$.

\section{Результаты}

В 1-й серии экспериментов при многократном интраназальном введении пептидов PGP и RERPGP здоровым крысам через 20 ч после последней процедуры установлено, что только пептид PGP способствовал статистически значимому повышению активности ТАП (на 201\%), сочетающемуся с увеличенной продукцией в крови метаболитов NO (на 27\%) по сравнению с соответствующим контролем. Через 168 ч после введения PGP - активирующее действие пептида на сосудистый эндотелий сохранялось. При применении RERPGP наблюдалось повышение уровня метаболитов NO только через 168 ч, при этом активность ТАП не изменялась в течение всего эксперимента (см. таблицу).

Следовательно, у здоровых крыс пептид RERPGP измененял функциональное состояние сосудистой стенки по продуктам NO лишь в отдаленные сроки, в то время как введение пептида PGP приводило к зна- чимому изменению обоих параметров (NO и ТАП), как сразу после многократного введения, так и на протяжении недели после отмены применения пептида.

Поскольку в эксперименте на здоровых животных выраженные эффекты выявлены у PGP, во 2-й серии, у животных с нарушением липидного и углеводного метаболизма, представляло интерес изучить влияние именно этого пептида.

Через 6 нед потребления животными ВКД, выявлялись нарушения в функционировании системы гемостаза и сосудистой стенки. Как видно на рис. 1, у контрольных крыс группы $1(\mathrm{MC}+\mathrm{NaCl})$ наблюдалось снижение активности ТАП (на 53\%) и уровня метаболитов NO (на 45\%) по сравнению со здоровыми животными. Это соответствует данным о развитии у животных с МС признаков дисфункции эндотелия и угнетении фибринолитической активности крови [8].

Семикратное введение PGP животным с МC (рис. $1, \boldsymbol{a})$ приводило к значительному увеличению активности ТАП как через 20 ч, так и через 168 ч после 7 -го применения пептида на $152 \%$ и $133 \%$ соответственно ( $p<0.01$ в обоих случаях) по сравнению с контролем («MC $+\mathrm{NaCl})$. Эти величины практически соответствовали значениям ТАП у здоровых крыс. Заслуживает внимания тот факт, что уровень метаболитов NO через 20 ч после воздействия PGP статистически значимо превышал этот показатель в контроле на $32 \%$. Этот эффект пептида через 168 ч не только сохранялся, но даже усиливался и составлял $144 \%$ от контрольных значений (рис. 1, б).

\section{Обсуждение}

Анализируя полученные результаты, необходимо отметить вероятную взаимосвязь между уровнем ТАП и метаболитами NO. Так, нами установлено, что эти параметры снижаются при развитии метаболических нарушений. Пептидные препараты глипролинового ряда, обладающие антикоагулянтным, фибринолитическим и антитромбоцитарным эффектом [11, 12], вмешиваясь

Таблица

Изменение активности тканевого активатора плазминогена (ТАП) и уровня метаболитов NO у здоровых крыс в разные сроки после семикратного введения PGP и RERPGP в ежедневной дозе 100 мкг/кг

\begin{tabular}{|c|c|c|c|c|}
\hline \multirow[t]{2}{*}{ Условия опыта } & \multicolumn{2}{|c|}{ Через 20 ч после 7-го введения } & \multicolumn{2}{|c|}{ Через 168 ч после 7-го введения } \\
\hline & ТАП, мM $^{2}$ & NO, MкM & ТАП, мM $^{2}$ & NO, MKM \\
\hline $\mathrm{NaCl}$ (контроль) & $12,0 \pm 0,7$ & $23,7 \pm 1,21$ & $12,2 \pm 0,6$ & $20,1 \pm 1,37$ \\
\hline RERPGP & $12,3 \pm 0,8$ & $25,8 \pm 1,25$ & $11,8 \pm 0,5$ & $24,8 \pm 1,42 *$ \\
\hline
\end{tabular}

Примечание. ТАП - активность тканевого активатора плазминогена, NO - уровень метаболитов (нитратов и нитритов) оксида азота; * $p<0,05$ по сравнению с соответствующим показателем в контрольной группе. 
в процессы фибринолиза и в функционирование сосудистого эндотелия, повышают не только активность ТАП, но и уровень метаболитов NO. Оксид азота синтезируется не только из L-аргинина NO-синтазами (NOSs), но и из его инертных метаболитов, нитритов и нитратов. Было показано [14], что длительный диетический дефицит нитрита/нитрата индуцирует развитие МС у мышей. Использование такой диеты в течение 3 мес вызывало висцеральное ожирение, дислипидемию и непереносимость глюкозы, в течение 18 мес - провоцировало увеличение массы тела, гипертензию, инсулинорезистентность и нарушение эндотелийзависимой вазодилятации при воздействии ацетилхолина, а в течение 22 мес - приводило к смерти из-за развития сердечно-сосудистых заболеваний. В то же время указанные отклонения устранялись одновременной добавкой к пище нитрата натрия, что было связано с эндотелиальной регуляцией NOS. Это свидетельствовало о том, что длительный дефицит нитритов/нитратов в рационе питания приводит к возникновению МС, сопровождающегося эндотелиальной дисфункцией и развитию в последующем сердечно-сосудистых заболеваний. Таким образом, это указывает на новую патогенетическую роль экзогенной системы производства NO при МС и его сосудистых осложнениях.

Рассматривая жировую ткань в качестве эндокринного органа, исследователи отмечают [15], что инги- битор активатора плазминогена-1 (ИАП-1), присутствующий в жировой ткани (адипоцитарный), выделяется в кровоток параллельно с увеличением жировой массы и отрицательно влияет на метаболизм в органах и тканях, в том числе и в сосудистой стенке. Поскольку ИАП-1 также является основным ингибитором ТАП, он индуцирует фибриногенез путем подавления внутрисосудистого и тканевого фибринолиза. Поэтому в наших исследованиях мы наблюдали снижение активности ТАП у крыс с МС, что, возможно, было обусловлено повышением ИАП-1. Под влиянием исследуемых пептидов активность ТАП усиливалась, что свидетельствовало о нормализации фибринолиза в условиях МС. При этом одновременно повышалась концентрация нитратов/нитритов, что позволяет нам считать глипролиновые пептиды перспективными фибринолитическими лекарственными средствами.

Обсуждая взаимосвязь МС с системой гемостаза и акцентируя внимание на функции эндотелия, отмечаем, что эндотелийзависимая вазодилатация нарушается при МС. Это в основном опосредовано сниженной экспрессией вазодилататоров (оксида азота и простациклина) с сопутствующим повышением вазоконстрикторов (эндотелина-1, ангиотензина II и тромбоксана А2). Перекрестное взаимодействие между активированным эндотелием и тромбоцитами приводит к протромботическому порочному циклу. Также при МС наблюдается $a$

\section{Активность тканевого активатора плазминогена}

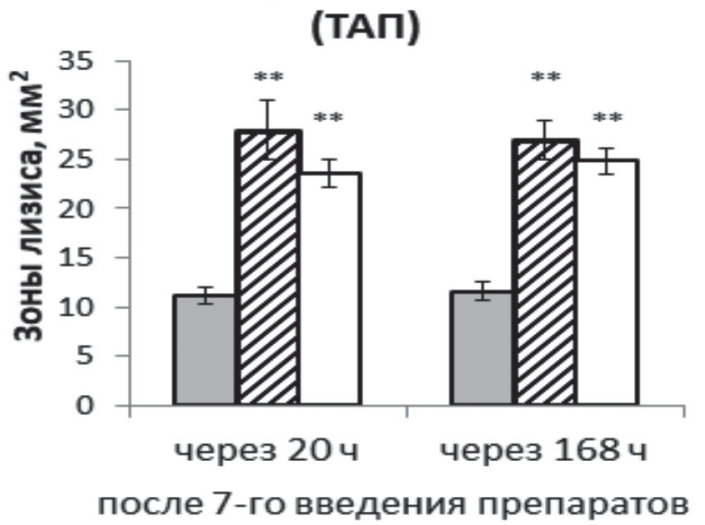

$\sigma$

\section{Уровень метаболитов NO}

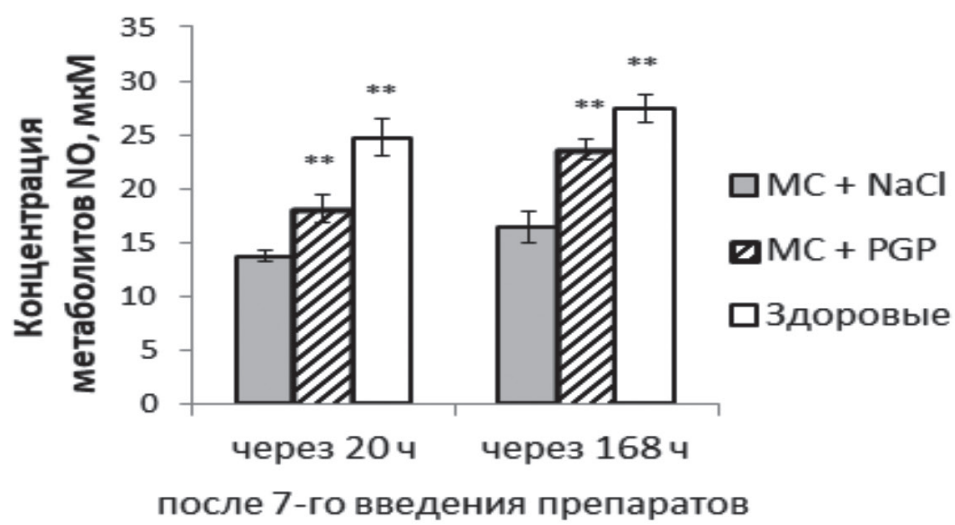

Рис. 1. Влияние 7-кратного интраназального введения пептида PGP на активность TAП (а) и уровень метаболитов NO (б) в плазме крови животных с метаболическим синдромом в зависимости от времени введения.

По оси абсцисс - активность ТАП и уровень метаболитов NO через 20 ч и 168 ч после последнего введения препаратов. ** $-p<0,01$ по сравнению с соответствующим показателем в контрольной группе («MC + $\mathrm{NaCl})$ ). 
усиленная коагуляция в сочетании с нарушением фибринолиза. Это проявляется высоким уровнем фибриногена, ИАП-1, эндотелиальной дисфункцией, повышением вязкости крови. Вопрос о взаимосвязи ИАП-1 и активности ТАП при МС требует дальнейшего изучения. -

В метаболизме органов и тканей важную роль играет аминокислота пролин, входящяя в состав глипролиновых пептидов [16]. Пролин и гидроксипролин - самые широко распространенные аминокислоты в белках коллагена. Пролин в сочетании с другой аминокислотой лизином и витамином С способен снижать концентрацию холестерина ЛПНП. Прием этих аминокислот эффективен при сердечно-сосудистых заболеваниях [17].

Мы предполагаем, что возможный механизм стимулируюшего влияния на сосудистый эндотелий исследованных нами пептидов глипролинового ряда обусловлен их структурными особенностями, а именно, наличием двух аминокислотных остатков пролина в составе молекул PGP и RERPGP .

\section{Заключение}

На основании экспериментальных исследований установлено, что пептиды глипролинового ряда - PGP и RERPGP оказывали стимулирующее действие на фибринолиз и функцию эндотелия как в норме, так и при патологии. Об этом свидетельствовало повышение активности тканевого активатора плазминогена и уровня метаболитов NO - нитратов и нитритов. Выявлено отличие в действии PGP и RERPGP у здоровых животных. В плазме крови крыс через 20 ч после интраназального семикратного введения пептида PGP установлено значительное возрастание активности ТАП и уровня метаболитов NO, которое сохранялось на протяжении 7 сут после отмены введения пептида, в то время как под влиянием RERPGP отмечался отсроченный эффект повышения только уровня нитратов и нитритов через 168 ч после последнего введения пептида. PGP также имел устойчивые выраженные эффекты в условиях метаболических нарушений у крыс, повышая активность фибринолитической системы и улучшая функцию эндотелия сосудов. Таким образом, пептид PGP защищал организм животных от прогрессирования дисфункции эндотелия и нарушения фибринолиза при МС.

\section{Литература \\ (п.п. 1; 4-9; 12; 14-17 см. References)}

2. Бабичев А.В. Роль эндотелия в механизмах гемостаза. Педиатр. 2013; 4(1): 122-7.

3. Метельская В.А., Гуманова Н.Г. Скриннинг-метод определения уровня метаболитов оксида азота в сыворотке крови человека. Клин. лаб. диагн. 2005; 6: 15-8.
10. Кузник Б.И., Хавинсон В.Х., Тарновская С.И., Линькова Н.С. Эпигенетическое действие регуляторных пептидов на цитокиновый профиль и систему гемостаза. Вестник гематологии. 2013; 9(2): 29-3.

11. Ляпина Л.А., Григорьева М.Е., Оберган Т.Ю., Шубина Т.А., Андреева Л.А., Мясоедов Н.Ф. Пептидная регуляция метаболических процессов при гиперхолестеринемических состояниях организма. Известия РАН. Серия биологическая. 2015; (6): 634-44. https://doi.org/10.7868/S0002332915060065

13. Ляпина Л.А., Григорьева М.Е., Оберган Т.Ю., Шубина Т.А. Teоретические и практические вопросы изучения функционального состояния противосвертывающей системы крови. М.: Адвансед Солюшнз; 2012.

\section{References}

1. Vieceli Dalla Sega F., Aquila G., Fortini F., Vaccarezza M., Secchiero P., Rizzo P., Campo G. Context-dependent function of ROS in the vascular endothelium: The role of the Notch pathway in shear stress. Biofactors. 2017; 43(4): 475-85. https://doi.org/10.1002/biof.1359

2. Babichev A.V. The role of endothelium in the mechanisms of hemostasis. Pediatr. 2013; 4(1): 122-7. (in Russian)

3. Metelskaya V.A., Gumanova N.G. Screening method for determining the level of nitric oxide metabolites in human serum. Klinicheskaya $i$ laboratornaya diagnostika. 2005; 6: 15-8. (in Russian)

4. Flavahan N.A. In the field of development - a new paradigm for under standing vascular disease. J. Cardiovasc Pharmacol. 2017; 69(5): 248-63.

5. Kraan J., Strijbos M.H., Sieuwerts A.M. A new approach for rapid and reliable enumeration of circulating endothelial cells in patients. J. Thromb. Haemost. 2012; 10: 931-39.

6. Vasilijevi A., Buzadi B., Kora A., Petrovi V., Jankovi A., Kora B. Beneficial effects of L-arginine-nitric oxide-producing pathway in rats treated with alloxan. J. Physiol. 2007; 584(3): 921-33.

7. Brzoska T., Tanaka-Murakami A., Suzuki Y., Sano H., Kanayama N., Urano T. Endogenously generated plasmin at the vascular wall injury site amplifies lysine binding site-dependent plasminogen accumulation in microthrombi. PLoS One. 2015; 10(3): e0122196. https://dio.org/10.1371/journal.pone.0122196

8. Shayo S.C., Kawade S., Ogiso K., Yoshihiko N. Strategies to ameliorate endothelial dysfunction associated with metabolic syndrome, where are we? Diabetes \& Metabiolc Syndrome: Clinical Research \& Reviews. 2019; 13(3): 2164-9. https://doi.org/10.1016/j. dsx.2019.05.005

9. Dentali F., Squizzato A., Ageno W. The metabolic syndrome as a risk factors for venous and arterial thrombosis. Seminars in Thrombosis and Hemostasis. 2009; 35(5): 451-7. https://doi.org/10.1055/ s-0029-1234140

10. Kuznik B.I., Chavinson V.Ch., Tarnonskaya S.I., Linkova N.S. Epigenetic effect of regulatory peptides on cytokine profile and hemostatic system. Vestnik Gematologii. 2013; 9(2): 29-33. (in Russian)

11. Lyapina L.A., Grigorieva M.E., Obergan T.Yu., Shubina T.A., Andreeva L.A., Myasoedov N.F. Peptide regulation of metabolic processes under hypercholesterinemia conditions of an organism. Izvestiya Rossiyskoy Akademii Nauk. Seriya Biologicheskaya. 2015; (6): 634-44. (in Russian) https://doi.org/10.7868/S0002332915060065

12. Myasoedov N.F., Lyapina L.A., Grigorjeva M.E., Obergan T.Y., Shubina T.A., Andreeva L.A. Mechanisms for glyproline protection 
DOI: 10.25557/0031-2991.2020.04.88-94

in hypercholesterolemia. Pathophysiology. 2016; 23(1): 27-3. https:// doi.org/10.1016/j.pathophys.2015.11.001

13. Lyapina L.A., Grigorieva M.E., Obergan T.Yu., Shubina T.A. Theoretical and practical issues of studying the functional state of the anticoagulation system of blood. [Teoreticheskie i prakticheskie voprosy izucheniya funktsionalnogo sostoyaniya protivosvertyvayushchey sistemy krovi]. Moscow; Advansed Solyushnz; 2012. (in Russian)

14. Kina-Tanada M., Sakanashi M., Arasaki A., Tsutsui M. Long-term dietary nitrite and nitrate deficiency causes metabolic syndrome, endothelial dysfunction, and cardiovascular death in mice. Nihon Yakurigaku Zasshi. 2018; 151(4): 148-54. https://doi.org/10.1254/ fpj. 151.148
15. Kaji H. Adipose tissue-derived plasminogen activator inhibitor-1 function and regulation. Compr. Physiol. 2016; 6(4): 1873-96. https:// doi.org/10.1002/cphy.c160004

16. Wu G., Bazer F.W., Burghardt R.C., Johnson G.A., Kim S.W., Knabe D.A. et al. Proline and hydroxyproline metabolism: implications for animal and human nutrition. Amino Acids. 2011; 40(4): 1053-63. https://doi.org/10.1007/s00726-010-0715-Z

17. Ivanov V., Roomi M., Kalinovsky T., Niedzwiecki A., Rath M. Anti-atherogenic effects of a mixture of ascorbic acid, lysine, proline, arginine, cysteine, and green tea phenolics in human aortic smooth muscle cells. J. Cardiovascular Pharmacol. 2007; 49(3): 140-45. https://doi.org/10.1097/FJC.0b013e3180308489

\section{Сведения об авторах:}

Оберган Тамара Юрьевна, канд. биол. наук, ст. науч. сотр. лаб. защитных систем крови им. проф. Б.А. Кудряшова каф. физиологии человека и животных биологического факультета ФГБОУ ВО МГУ им. М.В. Ломоносова, e-mail: tobergan@ mail.ru;

Григорьева Марина Евгеньевна, канд. биол. наук, доцент, вед. науч. сотр. лаб. защитных систем крови им. проф. Б.А. Кудряшова каф. физиологии человека и животных биологического факультета ФГБОУ ВО МГУ им. М.В. Ломоносова;

Ляпина Людмила Анисимовна, доктор биол. наук, проф., гл. науч. сотр. лаб. защитных систем крови им. проф. Б.А. Кудряшова каф. физиологии человека и животных биологического факультета ФГБОУ ВО МГУ им. М.В. Ломоносова;

Шубина Татьяна Александровна, канд. биол. наук, ст. науч. сотр. лаб. защитных систем крови им. проф. Б.А. Кудряшова каф. физиологии человека и животных биологического факультета ФГБОУ ВО МГУ им. М.В. Ломоносова;

Мясоедов Николай Федорович, доктор хим. наук, акад. РАН, руководитель отдела химии физиологически активных веществ ФГБУН «Институт молекулярной генетики РАН»;

Андреева Людмила Александровна, зав. сектором регуляторных пептидов отдела химии физиологически активных веществ ФГБУН «Институт молекулярной генетики РАН». 